\title{
Transient Neonatal Pustular Melanosis
}

National Cancer Institute

\section{Source}

National Cancer Institute. Transient Neonatal Pustular Melanosis. NCI Thesaurus. Code C116771.

A benign, self-limited eruption of vesicles, pustules and macules seen in newborns. The fluid-filled lesions typically rupture and resolve within 48 hours while the macular lesions may persist for months. 